\title{
Collapse Scenarios of High-Rise Buildings Using Plastic Limit Analysis
}

\author{
G. Liu, ${ }^{1}$ D. K. Liu, ${ }^{2}$ and W. K. Chow ${ }^{3}$ \\ ${ }^{1}$ Singapore-MIT Alliance, National University of Singapore, Singapore 117576, Singapore \\ ${ }^{2}$ Civil Engineering College, Harbin Engineering University, Harbin 150001, China \\ ${ }^{3}$ Department of Building Services Engineering, The Hong Kong Polytechnic University, Hung Hom, Kowloon, Hong Kong, China
}

Correspondence should be addressed to W. K. Chow, beelize@polyu.edu.hk

Received 21 August 2008; Revised 23 January 2009; Accepted 15 May 2009

Recommended by Ser Quek

The Twin Towers of the World Trade Center (WTC) in New York, USA collapsed on 11 September, 2001. The incident is regarded as the most severe disaster for high-rise buildings in history. Investigations into the collapse scenarios are still being conducted. Possible collapse scenarios assessed by local and international experts were reported. Another possible collapse scenario of the WTC based on two hypotheses was proposed in this paper, and the idea of plastic limit analysis was applied to evaluate the approximate limit load. According to the theory analysis and numerical calculations, a conclusion can be drawn that the large fires, aroused by the terrorist attack, play a significant role on the collapse of the WTC.

Copyright () 2009 G. Liu et al. This is an open access article distributed under the Creative Commons Attribution License, which permits unrestricted use, distribution, and reproduction in any medium, provided the original work is properly cited.

\section{The World Trade Center}

The World Trade Center (WTC) Twin Towers in New York, USA, that collapsed in the September 11 incident (e.g., $[1,2])$, were two of the top ten tallest buildings in the world. The South Tower was of height $1368 \mathrm{ft}$, and the North Tower was of height $1362 \mathrm{ft}$. Both towers had 110 stories with a standard story height of $3.676 \mathrm{~m}$. The two towers were identical in appearance as about $207 \mathrm{ft}$ square blocks. Each building had an area of $4.66 \times 10^{5} \mathrm{~m}^{2}$ and a weight of about $500000 \mathrm{t}$. Each side of the external wall was composed of 59 steel columns of side 14 inches densely arranged in 40inch intervals. The building exterior was covered with silver aluminium sheets. Under normal wind conditions, the roof oscillations can go up to $2.8 \mathrm{~m}$.

The WTC was built with strong steel structures with a good structural design. The buildings were still maintained in good condition many years after construction. They did not collapse immediately under the great impact of a plane. The Boeing 757 and 767 airplanes hijacked by the terrorists had take-off weights of $104 \mathrm{t}$ and $156 \mathrm{t}$ respectively, and they were piloted toward the towers at about $1000 \mathrm{~km} / \mathrm{h}$. As reported by the survivors, the buildings oscillated about $1 \mathrm{~m}$ after the plane crash. Both towers did not collapse immediately, giving some time for building occupants to escape. This also suggested that the physical impact might not be the factor leading to the collapse.

Many reports and papers appeared in literature with different views [2-17], including the concept from the point of mechanics with the idea of progressive collapse [18, 19]. Analysis of the previous literature [18] showed that if prolonged heating caused the majority of columns of a single floor to lose their load carrying capacity, the whole tower was doomed. Possible collapse scenarios of the WTC will be proposed in this paper with the focus on dynamic interaction between the upper part of the structure above the floors that have lost the load carrying capacity and the lower part below the critical floor which may induce the overall collapse of the towers.

\section{Possible Reasons for the Collapse}

Steel was used as the main structural material of the WTC. It is well-known that the strength of steel will reduce when heated up to temperatures above $500{ }^{\circ} \mathrm{C}$. Although fire protective coatings were applied over the structural materials, such coatings may not be effective under such 
a large fire. There were suggestions that the fire resistive coatings were torn off in the crash, or even that the coating layers were not thick enough, only being 1.5 inches.

The Boeing 757 airplane hitting the North Tower may have carried up to 10000 gallons (38000 litres) of fuel. It took off at the Boston International Airport at 7:59 am and hit the 94th to 98th floors of the North Tower at 8:46 am. The Boeing 767 airplane hitting the South Tower took off at the Boston International Airport at 8:14 am and hit the 78th to 84th floors of the South Tower at 9:03 am.

There were different views on how much liquid fuel was burnt in the fire. Since the airplanes hit the towers not long after taking off, there are some reports that only 16 percent of the fuel was consumed. Therefore, the remainder of the fuel may have been brought into the building. Flashover was onset to give a well-developed fire with high indoor temperatures. Long burning periods of such big fires would reduce the strength of the steel columns, especially at those floors being hit by the planes. Calculations [20] suggested that the combustibles stored inside the building, such as desks, furniture and paper gave a fire load at each level higher than the combustible aviation fuel spilled out from the aircraft.

Structural steel systems might be superior in constructing skyscraper buildings. However, in comparison to concrete structures, their poor fire resistance is a concern. Experimental studies indicated [21] that there is not much change in the properties of low-carbon steel at temperatures below $200^{\circ} \mathrm{C}$. However, above $200^{\circ} \mathrm{C}$, its elasticity decreases as temperature increases. Both the yielding stress and ultimate tensile stress decrease significantly as its deformation coefficient increases. At $500^{\circ} \mathrm{C}$, its modulus of elasticity is $50 \%$ of that at room temperature, and the load-bearing capacity decreases as the temperature increases. The fire resistance period would be reduced when the temperaturetime curves resulted are much higher than the standard curves on the fire resisting tests. Fire resistive coatings applied to the steel structures of the WTC might not be useful under such a large fire. As the steel was exposed to high temperatures for a prolonged period of time, its load-bearing capacity was reduced, until it finally collapsed.

The load-bearing structures of the WTC were the external columns and the central columns. The external columns bore $40 \%$ while the central columns bore $60 \%$ of the weight of the building. Since the South Tower was hit at a relatively lower position near the corner of the building, the external steel columns were seriously damaged. The North Tower was hit at a comparatively higher position, near the central part of the building. Because the damage done to the corner column of the South Tower was more severe than that done on the North Tower, the South Tower was easier to bend and form plastic hinges. This may explain why the North Tower collapsed after 1 hour 43 minutes, longer than the 1 hour 2 minutes for the South Tower.

Usmani et al. [22] investigated the stability of the axially restrained beam subjected to different fire conditions, and presented theoretical descriptions of the key phenomena that govern the behavior of composite framed structures in a fire. A finite-element model was also used by Usmani et al. [23] to investigate the stability of the Twin Towers of the World Trade Center under different fire scenarios. There, structural damages due to the terrorist attack were not included (it is to say the structure under dynamic loading was not reported). Analysis results suggested that thermal expansion effects are more severe than the effects due to loss of strength and stiffness of materials. The collapse mechanism discovered was a simple stability failure related directly to the effect of the fire. This mechanism did not depend upon the failure of structural connections.

In fact, fires in buildings would induce geometric (thermal expansion) and material effects (reduction in strength and stiffness) for structural elements. Computational modeling and analytical studies [23] illustrated that for large frame structures, the former effect dominates the behavior of the structure in the early stages; while the latter effect becomes more important near failure. As the floor truss system is very long, slender and not designed for planar forces (membrane or axial compression would dominate over bowing upon heating up the floor from top and bottom), the external columns would be pushed out. Eventually, increases in the membrane compressions due to thermal expansion and the high slenderness of the floor would lead to buckling of the floor. The deflections would be increased further over time. This change in the geometric shape of the floor system would reduce the axial capacity further, leading to a rapid loss of lateral restraint to the column. If several floors were affected by the fire, a very small load would buckle the external column in a different buckling mode as shown in Figure 1. This might be the reason why the instability initiated the collapse. In this paper, places where the external column lost stability are first assumed to give plastic hinges. Plastic Limit Analysis [24] can then be applied to calculate the least load that led to the collapse of the towers.

\section{A Proposed Study}

A study was proposed to simulate how the South Tower collapsed. As observed after the collapse, the debris was distributed evenly on two sides of the building site, which suggested that the collapse was not due to one load-bearing column; otherwise, the building would be tilted to one side. Due to the minimum of the total energy, three plastic hinges were assumed at locations as shown in Figure 2. Three plastic hinges might have resulted in the building under the action of vertical load. If $H$ is the total height of the lower levels after the building was hit by the plane, the following can be arrived:

$$
O A=B C=\frac{1}{2} A B=l=\frac{H}{4} .
$$

The buildings did not collapse immediately after the impact; only the parts hit were damaged. However, the large postflashover fire caused by the impact would cause the structural supporting elements to be reduced in strength gradually. After burning for over 1 hour, the upper levels lost support and collapsed. As the weight of the upper levels remained constant, only the structural stress of the part being hit diminished gradually. This could be interpreted as a static 


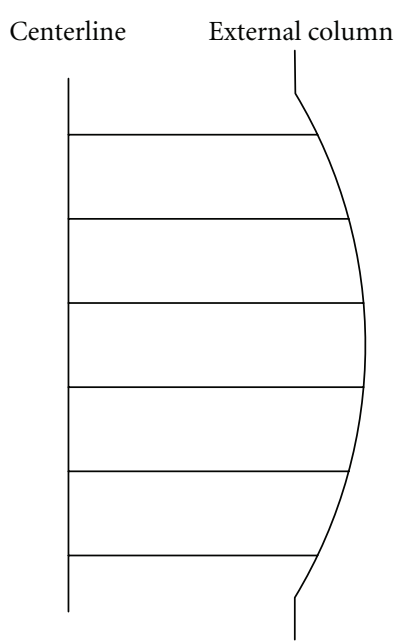

(a) Initial thermal expansion (and thermal bowing): columns pushed out as thermal expansion dominates

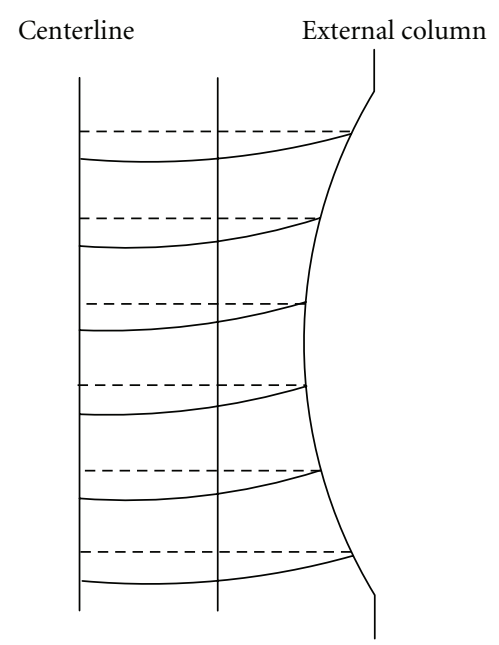

(b) Loss of stiffness in floors (by material softening and buckling induced by restrained thermal expansion)

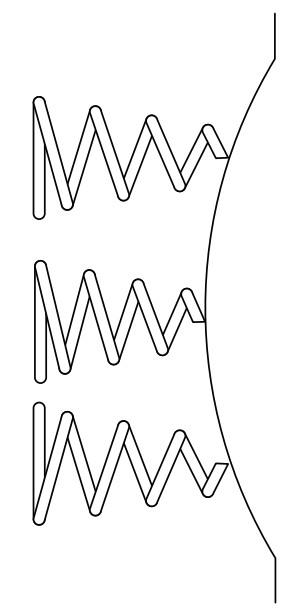

(c) New buckling model

Figure 1: Classical buckling of external steel columns condition with reduced lateral strains under fire.

load increasing process in which load was gradually added at constant structural intensity.

In this paper, based on the method of plastic limit analysis and Lagrangian Dynamics [24], the critical load for structural damage would be solved by the principle of the least virtual work. The conservation of momentum would give the instantaneous time for structural damage. This time is not the fire burning time nor is it the instant when the building collapsed. It is the time when the upper levels and the lower levels impacted together before the collapse. This quantity is difficult to be deduced from observation.

\section{The Concept of Plastic Hinges}

Linear elastic theory was applied for stress analysis and design of structures. The results are generally satisfactory, but there are some limitations on steel and aluminium structures. If the strain capacity is extended to much higher than the elastic limit, the Elastic Limit Analysis is not applicable.

Only the total moment and total stress are considered in the elastic limit analysis of the structure. Although it is easier for deducing the average stress, distribution of the stress is not uniform in practice. Under the condition of elastic limit analysis, the local high stress area may reach into the plastic range. This would make elastic limit analysis for structures very difficult.

Plastic Limit Analysis [24] would not have the above problems. The approach is independent of the elastic modulus $E$, remainder stress and loading history. It depends only on the structure and load orientation. In reviewing studies on the breakage of girder and plane frames, the failure loading depends only on the limit moment. There is no relation with the curvature of the structure.

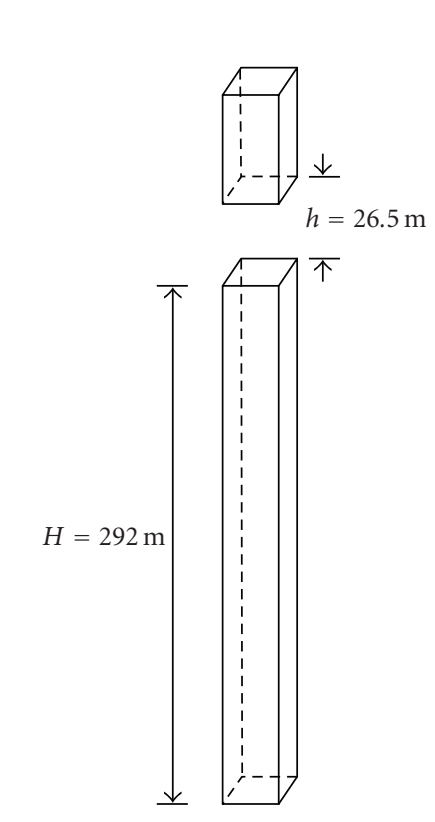

(a)

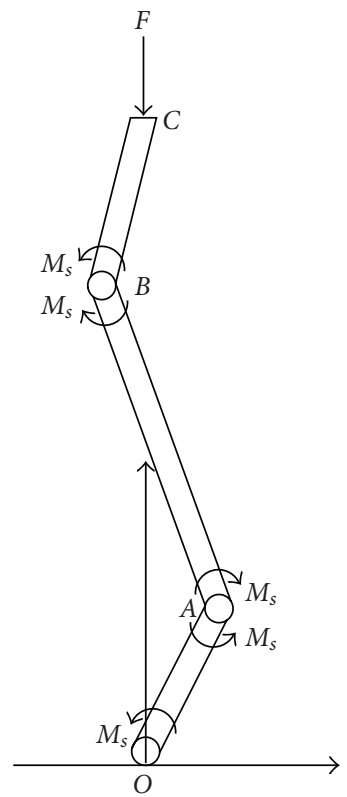

(b)
Figure 2: Proposed study (South Tower).

A feature of the absolute rigid-plastic material is that for a bearing-moment $M$ lower than the limit buckle moment $M_{0}$, the curvature is assumed to be zero. When $M \geq M_{0}$, the curvature can take any numerical values. The plastic hinges would do nothing except transfer the moment $M_{0}$.

Taking a beam with a rectangular cross-section as an example with dimensions shown in Figure 3 and the axes in Figure 4, the bearing pure-buckled moment is $M$. The distance between cross-sections 11,22 is $d x, z$ is the symmetry axis of the cross-section and $y$ is the neutral axis. 


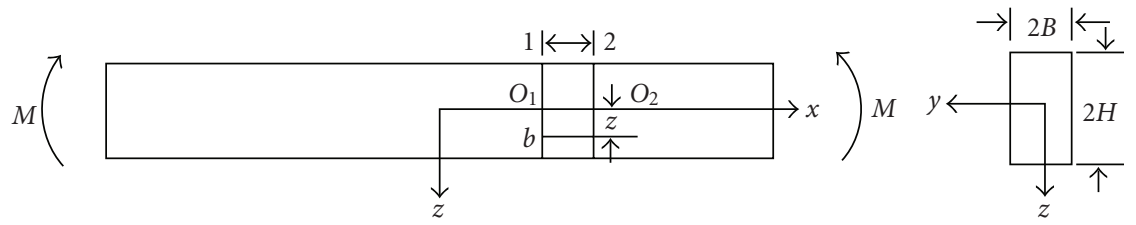

FIgURE 3: Rectangular cross-section beam under buckled moment.

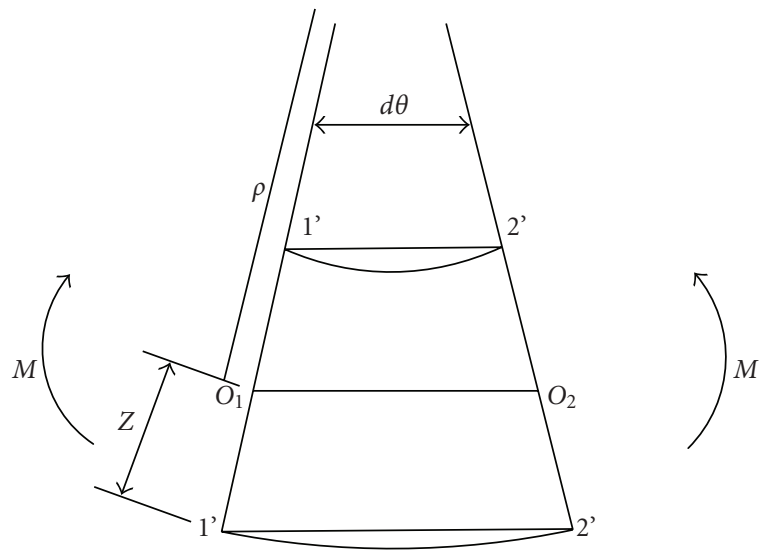

FIgURE 4: Drawing for the axis-bend metamorphosis of beam.

In buckling, $b b$ would change into $b^{\prime} b^{\prime}$, where $b^{\prime} b=(\rho+$ $z) d \theta, b b=d x=o_{1} o_{2}=\rho d \theta, \rho$ is the curvature radius of the neutrosphere and $d \theta$ is the relative degrees rotation. The strain of $b b$ is

$$
\varepsilon=\frac{(\rho+z) d \theta-\rho d \theta}{\rho d \theta}=\frac{z}{\rho}=K z .
$$

From the above, the strain $\varepsilon$ is directly proportional to $z$ :

$$
\begin{gathered}
\sigma=E \varepsilon=E \frac{z}{\rho}=K E z, \\
M=2 B \int_{-H}^{H} z \cdot \sigma_{x}(z) \cdot d z .
\end{gathered}
$$

For the absolute-elastic condition with Young's modulus $E$ and yielding stress $\sigma_{0}$, when $M$ is small enough, the stress is almost elastic, then

$$
M=\frac{4}{3} E B H^{3} K
$$

If $|\sigma|=\sigma_{0}$, at the lower edge and upper edge $(z= \pm H)$, buckling moment and curvature are

$$
M_{e}=\frac{4}{3} B H^{2} \sigma_{0}, \quad K_{e}=\frac{\sigma_{0}}{E H}
$$

Note that $M_{e}$ is not the bearing capacity of the beam.

If the moment increases gradually, the lower edge and upper edge would reach the yielding stress. However, the internal thread has not yet reached the yielding stress. The stress distribution will be changed. Therefore,

$$
M=4 B\left[\int_{0}^{\xi H}\left(\frac{\sigma_{0} z^{2}}{\xi H}\right) d z+\int_{\xi H}^{H} \sigma_{0} z d z\right]=\frac{2}{3} \sigma_{0} B H^{2}\left(3-\xi^{2}\right)
$$

If $M$ keeps on increasing, the plastic-elastic interactive surface $z=\xi h$ will tend to shift to the neutrosphere of the beam as in Figure 5. When $\xi=0$, the beam would be transformed into absolute plastic. It can be concluded that the limit buckle moment $M_{0}$ is

$$
M_{0}=2 \sigma_{0} B H^{2} .
$$

A detailed review on applying of plastic limit analysis in practical engineering problems was reported in literature [24].

\section{Plastic Limit Analysis on Collapses}

By simplifying the building into a uniform small rod and denoting the top static load as $F$, the active forces held by the system are the load $F$ and the bending moment $M_{s}$ due to the plastic hinges.

According to the principle of virtual displacement, the necessary and sufficient equilibrium condition for the system with ideal constraints is that the sum of the work done in any virtual displacements by the active forces acting on the system is zero. The mathematical expression is

$$
\sum_{i=1}^{\mathrm{N}} F_{i} \cdot \delta r_{i}=0
$$

where $F_{i}$ is the active force and $\delta r_{i}$ is the virtual displacement.

Taking an angle $\theta$ as the generalized coordinate, under the action of vertical load, if $F$ increases gradually to a critical point, the structure would be damaged. The critical value of $F$ is the critical value of the system balance. Following the principle of virtual displacement, virtual displacement can be written in the form of generalized coordinates:

$$
r_{i}=r_{i}\left(q_{1}, q_{2}, q_{3}, \ldots, q n, t\right), \quad(i=1,2,3, \ldots, n),
$$

where $q_{i}(i=1,2,3, \ldots, n)$ are generalized coordinates.

Taking variation on both sides of the above equation, then

$$
\delta r_{i}=\sum_{j=1}^{n} \frac{\partial r_{i}}{\partial q_{j}} \cdot \delta q_{j} .
$$




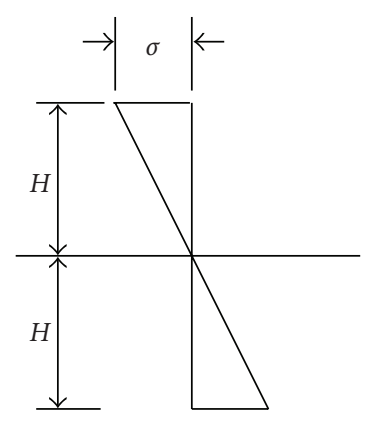

(a) Elastic

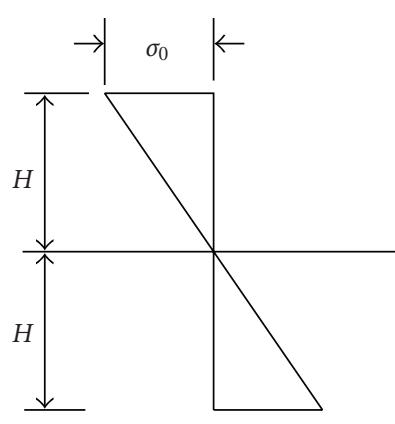

(b) Maximum elastic value

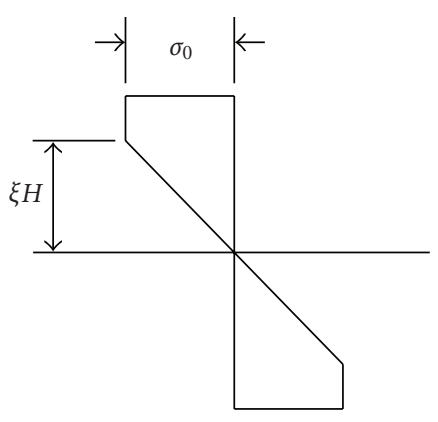

(c) Elasto-plastic value

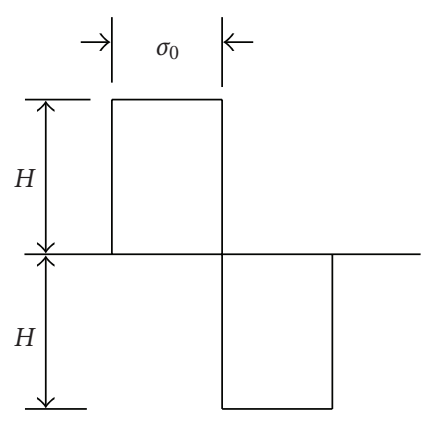

(d) Maximum plastic value

FIGURE 5: Distribution of stress in the rectangular cross-section beam.

Substituting the above into (8) of virtual work gives

$$
\sum_{j=1}^{n} \sum_{i=1}^{\mathrm{N}} F_{i} \cdot \frac{\partial r_{i}}{\partial q_{j}} \cdot \delta q_{j}=0,
$$

where $F_{i}$ represents the active force acting on any particle $i$, (11) is written as

$$
\sum_{j=1}^{n} Q_{j} \cdot \delta q_{j}=0
$$

where $\delta q_{j}$ is the generalized virtual displacement, and $Q_{j}$. $\delta q_{j}$ has the dimensions of work, $Q_{j}$ in the equation is referred to as the generalized force corresponding to the generalized coordinate $q_{j}$ :

$$
Q_{j}=\sum_{i=1}^{\mathrm{N}} F_{i} \cdot \frac{\partial r_{i}}{\partial q_{j}}
$$

For holonomic systems, the virtual displacements $\delta q_{j}$ of these $n$ generalized coordinates are independent, and all of them are nonzero small quantities.

$$
\text { From } \sum_{j=1}^{n} Q_{j} \cdot \delta q_{j}=0, \quad Q_{j}=0(j=1,2, \ldots, n) .
$$

That is to say, in the principle of virtual displacement represented by generalized coordinates, the necessary and sufficient equilibrium conditions for the complete systems with ideal constraints both the generalized forces of active forces acting on the system and their corresponding values to each generalized coordinate are zero.

The virtual work done by all active forces in the corresponding virtual displacements is represented by $\sum \delta W_{j}$ :

$$
\sum \delta W_{j}=\sum_{j=1}^{n} Q_{j} \cdot \delta q_{j}
$$

Then,

$$
Q_{j}=\frac{\sum \delta W_{j}}{\delta q_{j}}=0
$$

For the problem concerned in this paper, there is only one generalized coordinate, that is, angle $\theta$. (Different generalized coordinates such as: $\theta_{1}, \theta_{2}, \ldots, \theta_{n}$ can be assumed for other applications.) Taking the centers of gravity for $B C, B A$ and $O A$ sections at points $D, E, F$, respectively, for any small displacement $\delta \theta$,

$$
F \cdot 4 l \delta \theta=5 M_{S} \delta \theta .
$$

From (17), the generalized force along $\theta$ is

$$
Q_{\theta}=\frac{F \cdot 4 l \delta \theta-5 M_{S} \delta \theta}{\delta \theta}=4 F l-5 M_{S}=0 .
$$

Therefore,

$$
F=\frac{5 M_{S}}{4 l}=\frac{5 M_{S}}{H} .
$$

Equation (19) is the correlation equation of $M_{S}, F$ at system equilibrium under the action of maximum bending moment $M_{S}$ without including the weight of the structure. The system would be broken when

$$
F \geq \frac{5 M_{S}}{H} .
$$

As the WTC was built mostly by steel columns, high-performance steel $K 20 M_{n} S_{i}$ of yielding stress $\sigma_{s}=$ $400 \mathrm{~N} / \mathrm{mm}^{2}$ and tensile strength $\sigma_{b}=600 \mathrm{~N} / \mathrm{mm}^{2}$ are selected in this study. As $\sigma_{s}<\sigma_{b}$, when the external steel column buckled, the areas in compression were destroyed first, followed by the areas in tension. The layout of the loadbearing structure of WTC is shown in Figure 6. Building characteristics are as follows.

(i) South Tower: $1368 \mathrm{ft}$ or $417 \mathrm{~m}, 110$ stories, $500000 \mathrm{t}$, hit at 78th to 84th floors.

(ii) North Tower: $1362 \mathrm{ft}$ or $415 \mathrm{~m}, 110$ stories, $500000 \mathrm{t}$, hit at 94th to 98th floors.

For the South Tower,

$$
\begin{aligned}
& m=\frac{110-85+1}{110} \times 500000 \mathrm{t}=118182 \mathrm{t}, \\
& h=\frac{84-78+1}{110} \times 417 \mathrm{~m}=26.5 \mathrm{~m}, \\
& H=\frac{77}{110} \times 417 \mathrm{~m}=291.9 \approx 292 \mathrm{~m} .
\end{aligned}
$$




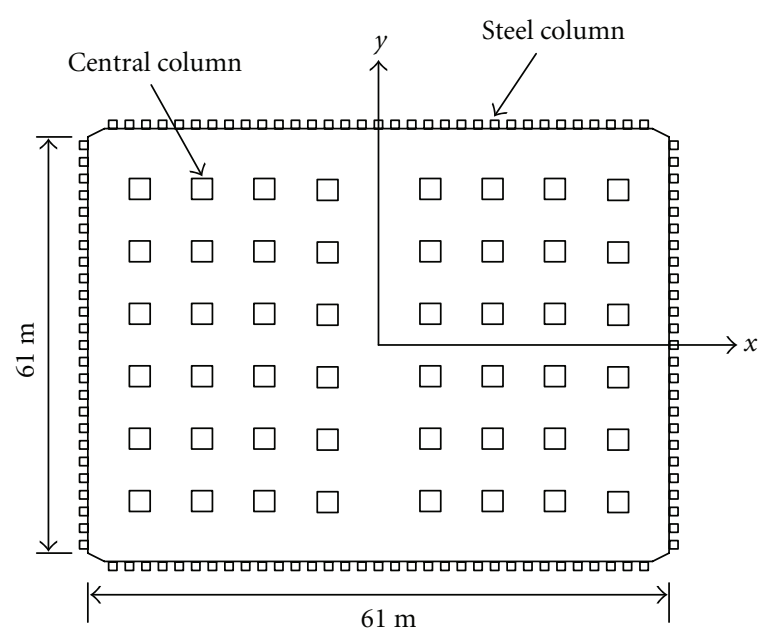

Figure 6: Load-bearing structure of WTC.

For the North Tower, levels

$$
\begin{aligned}
m^{\prime} & =\frac{110-99+1}{110} \times 500000 \mathrm{t}=54545 \mathrm{t}, \\
h^{\prime} & =\frac{98-94+1}{110} \times 415 \mathrm{~m}=18.8 \mathrm{~m}, \\
H^{\prime} & =\frac{93}{110} \times 415 \mathrm{~m}=350.86 \approx 351 \mathrm{~m} .
\end{aligned}
$$

Before the free falling upper levels acting on the lower

$$
h=\frac{1}{2} g \cdot t^{2}, \quad v=g \cdot t
$$

gives: $v=\sqrt{2 g h}, p=m v=m \sqrt{2 g h}, t=\sqrt{2 h / g}$.

From the conservation of momentum, the impulse to the particle due to external force is equal to the change in particle momentum. For rigid-plastic model, elastic energy due to external force is ignored:

$$
\begin{aligned}
F \cdot \Delta t & =p=m v_{\text {initial }}-m v_{\text {terminal }} \\
& =m \sqrt{2 g h}-\mathrm{m} v_{\text {terminal }} .
\end{aligned}
$$

The momentum of the free falling upper levels of the South Tower is

$$
\begin{aligned}
p & =118182 \times 10^{3} \mathrm{~kg} \times \sqrt{2 \times 9.8 \mathrm{n} / \mathrm{kg} \times 26.5} \mathrm{~m} \\
& \approx 2.69 \times 10^{9} \mathrm{~kg} \cdot \mathrm{m} / \mathrm{s} .
\end{aligned}
$$

The momentum of the free falling upper levels of the North Tower is

$$
\begin{aligned}
p^{\prime} & =54545 \times 10^{3} \mathrm{~kg} \times \sqrt{2 \times 9.8 \mathrm{n} / \mathrm{kg} \times 18.8} \mathrm{~m} \\
& \approx 1.06 \times 10^{9} \mathrm{~kg} \cdot \mathrm{m} / \mathrm{s} .
\end{aligned}
$$

The buckled breakage of the cross-section of the towers might be along the $x$ inertia axis or the $y$ axis. As such detailed information is not available, they are taken to be the same.

Use

$$
\begin{gathered}
\sigma_{s} \cdot \sum x_{i} \cdot A_{i}+\sigma_{b} \cdot \sum x_{j} \cdot A_{j}=M_{S}, \\
\sum x_{i} \cdot A_{i}=\sum x_{j} \cdot A_{j},
\end{gathered}
$$

where $x_{i}$ is the distance between the center of the pressed column and the center of the tower's cross-section; $x_{j}$ is the distance between the center of the tensile column and the center of the tower's cross-section; $A_{i}$ is the cross-sectional area of the pressed column; and $A_{j}$ is the cross-sectional area of the tensile column.

The maximum bending moment of the plastic hinges can be obtained when the yielding stress $\sigma_{s}$ of all the pressed columns reached $400 \mathrm{~N} / \mathrm{mm}^{2}$, and yielding stress of all the tensile columns $\sigma_{b}$ reached $600 \mathrm{~N} / \mathrm{mm}^{2}$. As we know, there were steel columns on the four sides and the central part of the building. Since the external steel columns were square in shape of length $b=14$ inches (about $0.3556 \mathrm{~m}$ ) and arranged at intervals of about $1.016 \mathrm{~m}$, the longest distance between the external column axis and the centroid of the plane load-bearing structure was about $103.5 \mathrm{ft}$ (or $31.5 \mathrm{~m}$ ). It was reported $[25,26]$ that the central columns were not $14 \times 36$ inches $^{2}$. The bending theory in plastic limit analysis was applied to calculate the hollow tubes. The results would be the same for solid ones by subtracting two different solid columns with one column of dimension corresponding with the outer radius of the hollow tube. The dimension of the other is the same with the outer radius of the hollow tube. For the twin towers (207 feet in each side), with such small dimensions of the hollow columns, the slender hollow columns were taken as solid rectangles. So the area of the central column was: $b \times h=14$ inches $\times 36$ inches (or $0.3556 \mathrm{~m} \times 0.9144 \mathrm{~m})$. This gives

$$
\begin{aligned}
\sum x_{i} \cdot A_{i}= & \sum x_{j} \cdot A_{j} \approx\left(59 x_{\max } \cdot a^{2}+\sum_{i=1}^{29} 1.016 i \cdot a^{2}\right) \\
& +6 b h \cdot(21+15+6+3),
\end{aligned}
$$

where

$$
\begin{aligned}
x_{\max } & =100 \mathrm{ft}=31.5 \mathrm{~m}, \\
a^{2} & =0.3556^{2}, \\
b h & \approx 0.3556 \mathrm{~m} \times 0.9144 \mathrm{~m},
\end{aligned}
$$

Therefore,

$$
\sum x_{i} \cdot A_{i}=\sum x_{j} \cdot A_{j} \approx 371.08 \mathrm{~m}^{3}
$$

The maximum bending moment of plastic hinges can be obtained by using

$$
\left(\sigma_{s} \cdot \sum x_{i} \cdot A_{i}+\sigma_{b} \cdot \sum x_{j} \cdot A_{j}\right)=M_{S} .
$$

From (19), that is, $F_{\text {critical }}=(5 / H)\left(M_{s} \eta\right)$, the maximum load can be calculated with $\eta=1$. Here $\eta$ is taken as 1 . 


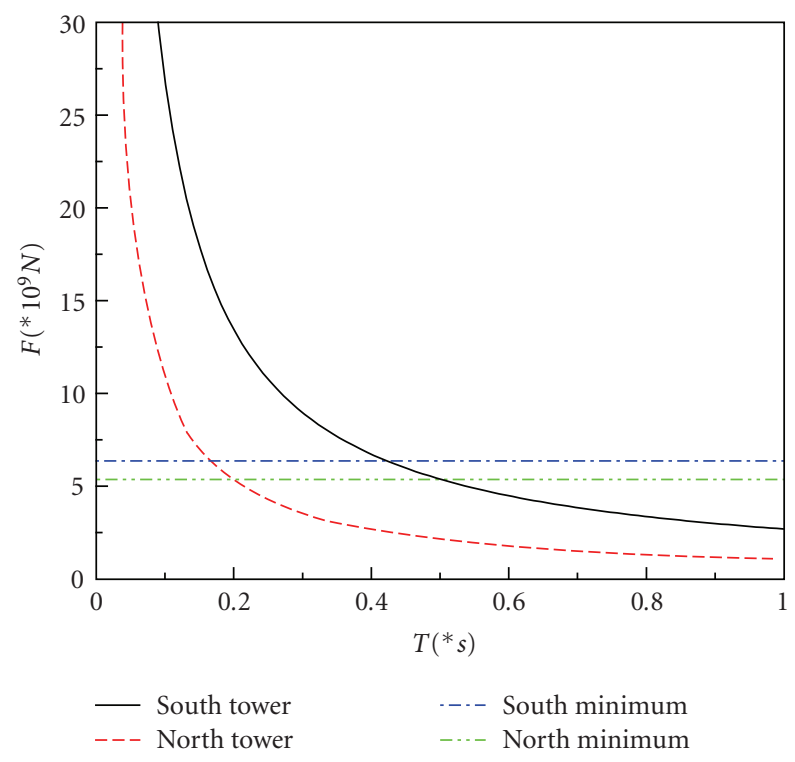

FIgURE 7: Critical load curve under rigid impact action.

In practice, when exposed to high temperature, the yielding stress of the buckled steel would decrease gradually, that is, $\eta \leq 1$ with $\eta$ diminishing slowly. It should be pointed out that if we can obtain the approximated estimation of $\eta$ versus the influence of temperature of the conflagrant part and the conductive coefficients of the heat transfer through the structure, we can calculate the precise critical load that will induce the collapse of the tower. Then, the action time $\Delta t$ can be calculated through (24) in above.

As $\sigma_{s}$ is not equal to $\sigma_{b}$, the central axis was not at the center during the towers' collapse. The maximum bending moment of plastic hinges is calculated by

$$
\sum \sigma_{s} \cdot x_{i} \cdot A_{i}=\sum \sigma_{b} \cdot x_{j} \cdot A_{j}, \quad x_{i} \neq x_{j} .
$$

In this paper, $\sigma_{s}$ is assumed to be equal to $\sigma_{b}$ during collapse, as $\sigma_{s}=\sigma_{b}=\left(400 \mathrm{~N} / \mathrm{mm}^{2}+600 \mathrm{~N} / \mathrm{mm}^{2}\right) / 2=$ $500 \mathrm{~N} / \mathrm{mm}^{2}$, so the neutral axis was in the center of the tower's cross-section $\left(x_{i}=x_{j}\right)$. The approximate bending moment can be deduced when we approximately set $\eta=1$.

(i) For the South Tower, when $\sigma_{s}=\sigma_{b}=500 \mathrm{~N} / \mathrm{mm}^{2}$ and the interaction between the free falling upper levels and the lower levels was a complete rigid impact action (i.e., $\left.v_{\text {terminal }}=0\right)$ :

$$
\begin{aligned}
M_{S} & =371.08 \mathrm{~m}^{3} \times\left(500 \mathrm{~N} / \mathrm{mm}^{2}+500 \mathrm{~N} / \mathrm{mm}^{2}\right) \\
& \approx 371.08 \times 10^{9} \mathrm{~N} \cdot \mathrm{m}, \\
F_{\text {south,min }} & =\frac{5}{H}\left(M_{S} \eta\right)=\frac{5 \times 371.08 \times 10^{9} \mathrm{~N} \cdot \mathrm{m}}{292 \mathrm{~m}} \\
& =6.35 \times 10^{9} \mathrm{~N} .
\end{aligned}
$$

The downward weight of the upper levels due to gravity was

$$
G=1.158 \times 10^{9} \mathrm{~N} .
$$

Comparing $G$ to $F_{\min }$ would give

$$
\frac{G}{F_{\text {south,min }}}=0.182 \text {. }
$$

When the yielding stress $\sigma_{s}^{\prime}$ of the several steel columns of the floor affected by the fire became $18.2 \%$ of the initial intensity $\sigma_{s}$, that is, $\eta=0.182$, the South Tower may collapse:

$$
\Delta t_{\max }=\frac{P}{F}=\frac{2.69 \times 10^{9} \mathrm{~kg} \cdot \mathrm{m} / \mathrm{s}}{6.35 \times 10^{9} \mathrm{~N}} \approx 0.42 \mathrm{~s}
$$

(ii) For the North Tower, when the interaction between the free falling upper levels and the lower levels was a complete rigid impact action (i.e., $v_{\text {terminal }}=0$ ):

$$
\begin{aligned}
F_{\text {north,min }} & =\frac{5}{H}\left(M_{S} \eta\right)=\frac{5 \times 371.08 \times 10^{9} \mathrm{~N} \cdot m}{351 \mathrm{~m}} \\
& =5.28 \times 10^{9} \mathrm{~N} .
\end{aligned}
$$

The downward weight of the upper levels due to gravity was:

$$
G^{\prime}=0.53 \times 10^{9} \mathrm{~N} .
$$

Comparing $G^{\prime}$ to $F_{\text {north,min }}$ would give

$$
G^{\prime} / F_{\text {north,min }}=0.100 \text {. }
$$

So when the yielding stress $\sigma_{s}^{\prime}$ of the several steel columns of the fire floor became $10 \%$ of the initial intensity, that is, when $\eta^{\prime}=0.100$, the North Tower might collapse:

$$
\Delta t_{\max }=\frac{P}{F}=\frac{1.06 \times 10^{9} \mathrm{~kg} \cdot \mathrm{m} / \mathrm{s}}{5.28 \times 10^{9} \mathrm{~N}} \approx 0.2 \mathrm{~s} .
$$

\section{Data Analysis}

From the data above, we can draw some conclusions. The limit loads of the South and North Towers are $6.35 \times 10^{9} \mathrm{~N}$ and $5.28 \times 10^{9} \mathrm{~N}$, respectively. The towers will not collapse until the yielding stress $\sigma_{s}^{\prime}$ of several steel columns in the fire affected floor became $18.2 \%$ for the South Tower $(10 \%$ for the North Tower) of the initial intensity $\sigma_{s}$, that is, when $\eta=0.182$ and $\eta^{\prime}=0.100$, respectively. That is to say, the external static load (the gravity of the upper floors) is much lower than this limit load. Without the large fire, which undermines the stiffness of the steel column on the lower section, the steel columns of the structure would be strong enough to support the buildings.

The continuous fire impaired the stiffness of the steel column on the lower zone as well as damaging the structure of the region. After exposure to fire for 1 hour, both these two domains lost the strength, which resulted in a smaller limit load $F_{\text {south,min }}\left(F_{\text {north,min }}\right)$, and changed the static loading into dynamic impacting. 


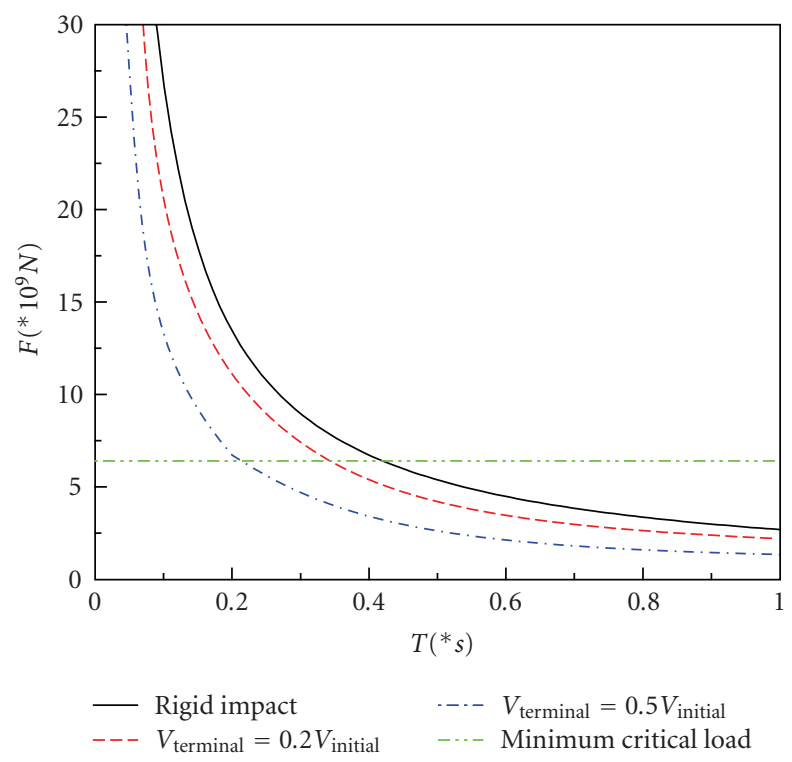

(a) South Tower

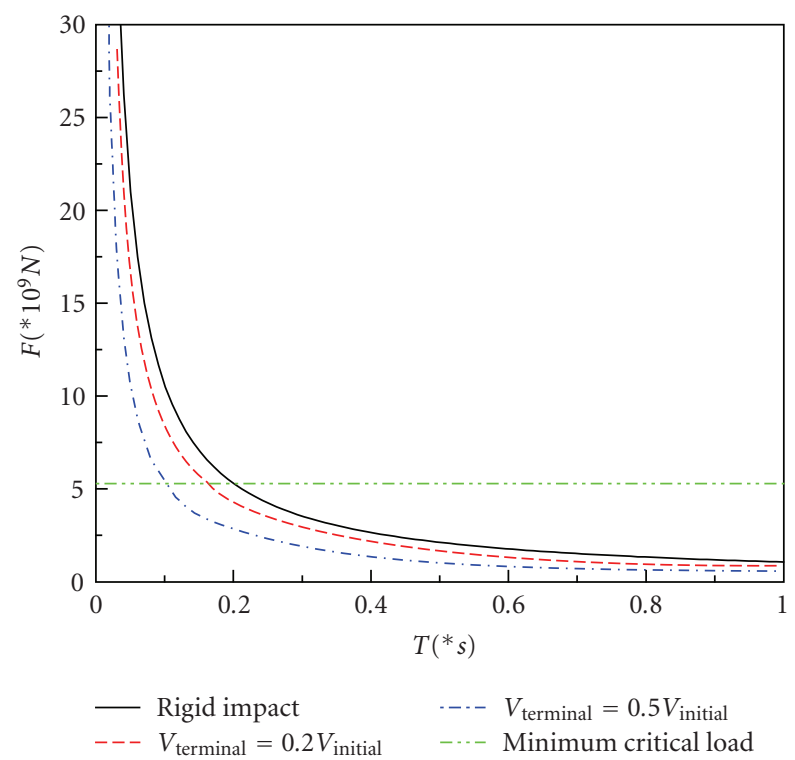

(b) North Tower

Figure 8: Critical load curves under noncomplete rigid impact action.

If we set $F_{\text {south,min }}$ and $F_{\text {north,min }}$ as constants (to ensure no decrease of the stiffness for the lower floors), and the interaction between the upper impact load and lower levels a complete rigid impact action (i.e., after the interaction, the terminal velocity of the free falling upper levels $v_{\text {terminal }}$ is 0 ), then we have the following.

(i) For the South Tower, if the interaction time between the upper and lower levels $\Delta t \leq \Delta t_{\max } \approx 0.42 \mathrm{~s}$, the building would collapse. If the interaction time $\Delta t \geq$ $0.42 \mathrm{~s}$, the building would collapse only when the upper and lower levels interactive force $F \geq F_{\text {south,min }}$. (ii) For the North Tower, if the interaction time between the upper and lower levels $\Delta t \leq \Delta t_{\max } \approx 0.2 \mathrm{~s}$, the building would collapse. If the interaction time $\Delta t \geq 0.2 \mathrm{~s}$, the building would collapse only when the upper and lower levels interactive force $F \geq F_{\text {north,min }}$.

(iii) From Figure 7, when the values of $F$ and $\Delta t$ fall into the upper right region above the curve, the South and North Towers would collapse.

The interaction between the upper impact load and the lower levels was not a complete rigid impact action (i.e., after the interaction, the terminal velocity of the free falling upper levels $v_{\text {terminal }} \neq 0$ ), only when the interaction time was so short that the interactive force would be sufficiently large to cause the collapse of the building as in Figure 8. On the contrary, the prolonged combustion impaired the stiffness of the lower floors seriously, which caused the collapse.

\section{Conclusions}

In this paper, an idea of Plastic Limit Analysis maybe not limited to that which was applied to study a possible collapse scenario of the World Trade Center. It might be concluded at this movement that the collapse of the two WTC towers were due to a large fire. The strength and stiffness of the structure should be strong enough to support the entire weight of the upper floors. However, if the load-bearing capacity of the structure decreased gradually due to a fire, the yielding stress and ultimate tensile stress of the steel columns would also decrease to have the two towers collapsed. As the two towers were hit at different places, the times for the two towers to collapse were different.

\section{References}

[1] J. R. Asker, "Washington outlook," Aviation Week \& Space Technology, p. 33, September 2001.

[2] W. K. Chow and W. Y. Hung, "Possible collapse scenarios of the World Trade Center twin towers," Asian Fire Fighting \& Security Journal, pp. 24-37, 2005.

[3] World Trade Center Building Performance Study, Federal Emergency Management Agency FEMA, 2002.

[4] J. G. Quintiere, M. di Marzo, and R. Becker, "A suggested cause of the fire-induced collapse of the World Trade Towers," Fire Safety Journal, vol. 37, no. 7, pp. 707-716, 2002.

[5] W. K. Chow, "Speech on 'Essential fire safety provision for highrise buildings in Hong Kong: lessons learnt from World Trade Centre incident," Hong Kong Institute of Construction Managers, Hong Kong, January 2002.

[6] W. G. Corley, "Lessons learned on improving resistance of buildings to terrorist attacks," Journal of Performance of Constructed Facilities, vol. 18, no. 2, pp. 68-78, 2004.

[7] R. G. Rehm, W. M. Pitts, H. R. Baum, et al., "Initial model for fires in the World Trade Center Towers," in Proceedings of the 7th International Symposium on Fire Safety Science, D. D. Evans, Ed., pp. 25-40, International Association for Fire Safety Science (IAFSS), Boston, Mass, USA, June 2003.

[8] J. Milke, "Study of building performance in the WTC disaster," Fire Protection Engineering, vol. 18, pp. 6-16, 2003.

[9] J. G. Quintiere, “Opportunities to learn from 9/11," Fire Protection Engineering, vol. 21, pp. 27-30, 2004. 
[10] J. G. Quintiere, "Review of NIST WTC investigation," Skyscraper Safety Campaign, pp. 17-31, 2004.

[11] "Latest findings from NIST World Trade Center investigation released. Leading collapse sequence for each WTC tower defined," NIST and the World Trade Center, National Institute of Standards and Technology, Gaithersburg, Md, USA, 2004.

[12] Documentary information received by NIST, News and Events, NIST and the World Trade Center, National Institute of Standards and Technology, Gaithersburg, Md, USA, 2004.

[13] "Project 2-Baseline structural performance and aircraft impact damage analysis," Federal Building and Fire Safety Investigation of the World Trade Center Disaster, NIST and the World Trade Center, National Institute of Standards and Technology, Gaithersburg, Md, USA, 2004.

[14] "Project 6-Structural Fire Response and Collapse Analysis," Federal Building and Fire Safety Investigation of the World Trade Center Disaster, NIST and the World Trade Center, National Institute of Standards and Technology, Gaithersburg, Md, USA, 2004.

[15] "Key findings of NIST's June 2004 progress report on the federal building and fire safety investigation of the World Trade Center disaster," Tech. Rep., NIST and the World Trade Center, National Institute of Standards and Technology, Gaithersburg, Md, USA, 2004.

[16] W. Y. Hung and W. K. Chow, "Possible collapse scenarios of World Trade Center twin towers," in Proceedings of the Subgroup 4: "Smoke Movement and Toxic Harmful Gases Transfer in Fire" of the National 973 Project "Fire Dynamics and Fundamentals of Fire Safety", pp. 16-24, Hefei, China, May 2004.

[17] "Collapse of the World Trade Center Towers," Final Report. Federal Building and Fire Safety Investigation of the World Trade Center Disaster, National Institute of Standards and Technology, National Construction Safety Team, Gaithersburg, Md, USA, September 2005.

[18] Z. P. Bažant and Y. Zhou, "Why did the world trade center collapse? Simple analysis," Journal of Engineering Mechanics, vol. 128, no. 1, pp. 2-6, 2002.

[19] Z. P. Bažant and M. Verdure, "Mechanics of progressive collapse: learning from World Trade Center and building demolitions," Journal of Engineering Mechanics, vol. 133, no. 3, pp. 308-319, 2007.

[20] J. Roberts, "After the towers- the future for tall buildings. Designing against disaster," Ingenia, vol. 17, pp. 7-9, 2003.

[21] "Behaviour of steel framed structures under fire conditions," Tech. Rep., DETRPIT Project, School of Civil and Environmental Engineering, University of Edinburgh, Edinburgh, UK, 2000, http://www.civ.ed.ac.uk/research/fire/public_html/ Cardington/SM3.pdf.

[22] A. S. Usmani, J. M. Rotter, S. Lamont, A. M. Sanad, and M. Gillie, "Fundamental principles of structural behaviour under thermal effects," Fire Safety Journal, vol. 36, no. 8, pp. 721-744, 2001.

[23] A. S. Usmani, Y. C. Chung, and J. L. Torero, "How did the WTC towers collapse: a new theory," Fire Safety Journal, vol. 38, no. 6, pp. 501-533, 2003.

[24] P. G. Hodge, Plastic Analysis of Structure, Science Press, Beijing, China, 1966.

[25] W. Cheng and J. K. Wu, "Collapse process of World Trade Tower from the viewpoint of explosion mechanics," Mechanics in Engineering, vol. 23, no. 6, pp. 73-75, 2001.

[26] D. W. Liu, "The mechanics study for the collapse of the World Trade Tower," Science Technology and Engineering, vol. 5, no. 6, pp. 1671-1815, 2005. 

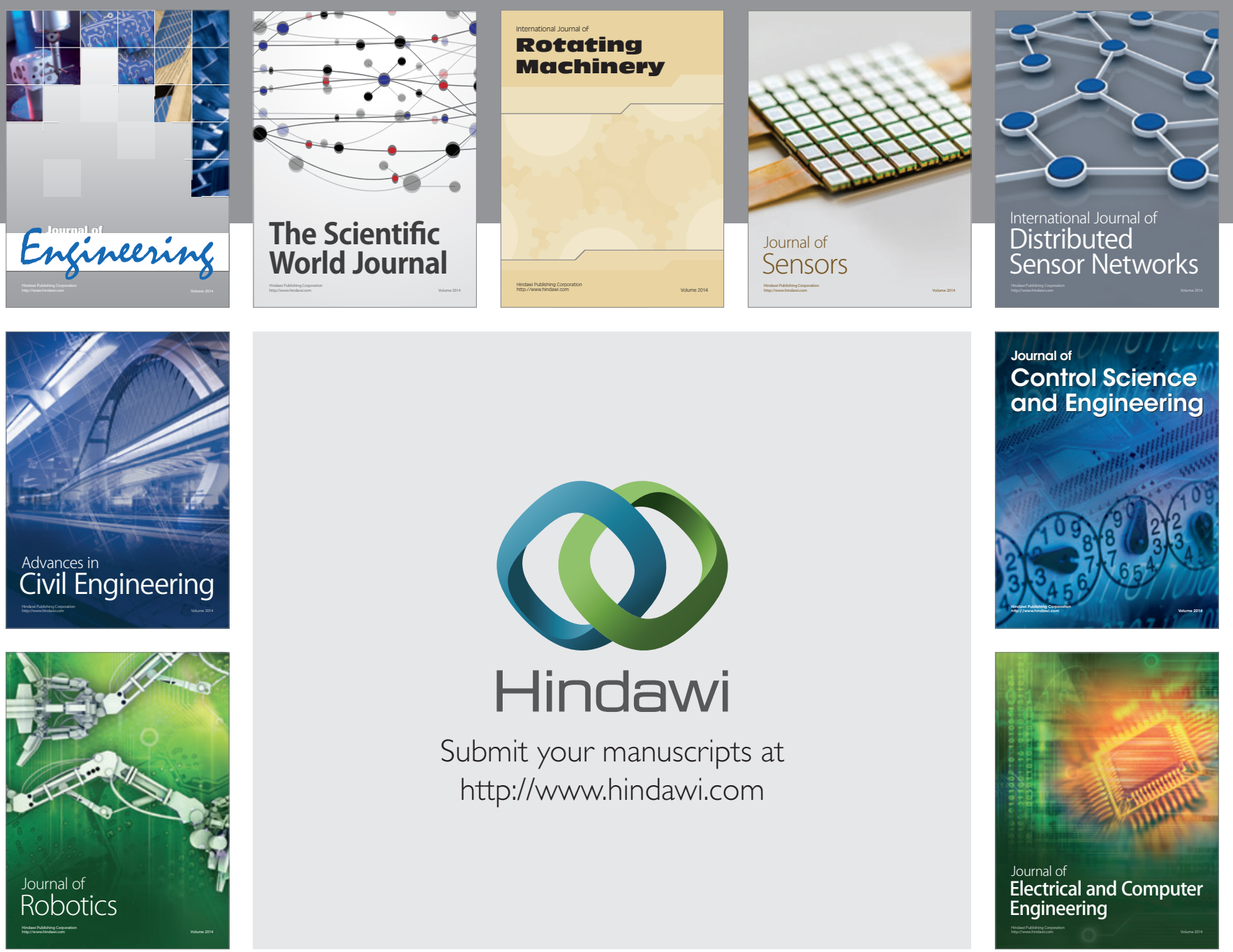

Submit your manuscripts at

http://www.hindawi.com
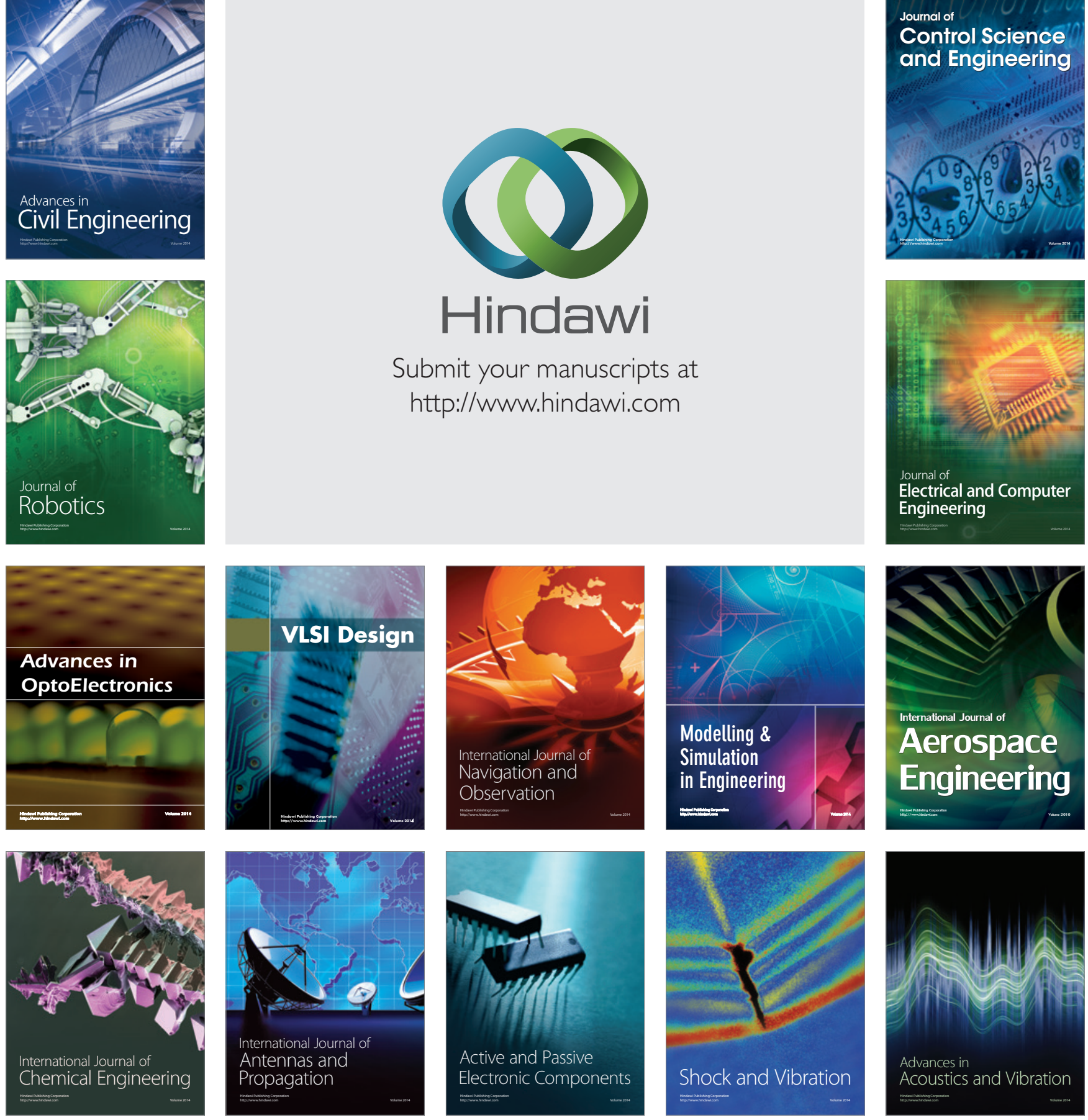